\title{
UNA FALCATA DAMASQUINADA PROCEDENTE DE LA PLANA DE UTIEL (VALENCIA): ESTUDIO TIPOLÓGICO, TECNOLÓGICO Y RESTAURACIÓN
}

\author{
ALBERTO J. LORRIO* \\ SALVADOR ROVIRA** \\ FRANCISCO GAGO BLANCO** \\ * Universidad de Alicante \\ alberto.lorrio@ua.es \\ ** Museo Arqueológico Nacional \\ srl@man.es
}

\begin{abstract}
Estudio tipológico y metalográfico de una falcata ibérica con decoración damasquinada, cuyo motivo principal es una escena de lucha entre un jabalí y un felino. La hoja del arma está formada por un alma de hierro dulce recubierta por una lámina de acero y una tercera varilla que forma el dorso o contrafilo, todas ellas soldadas a la calda y forjadas. Por el contexto del hallazgo, parece que debió formar parte de un depósito, seguramente de herrero. Se describe también el tratamiento de restauración aplicado a la falcata.
\end{abstract}

This is a typological and metallographical study of an lberic falcata sword decorated with a silver damascene work. The main decorative motif is the fight between a wild boar and a feline. The blade is made up by a wrought iron core covered by a thin sheet of steel, with a third rod in the back, all of them piled and forged. The archaelogical context of the finding suggests an ironsmith's hoard. We also describe the process of restoration of the sword.

\section{INTRODUCCIÓN}

El presente trabajo aborda el análisis de una pieza excepcional, una falcata ibérica con decoración damasquinada (fig. 1), procedente de la comarca valenciana de la Plana de Utiel. Se trata de un hallazgo casual, aparecido al realizar tareas agrícolas, en un terreno situado a los pies de la ladera meridional del Cerro de la Peladilla (Fuenterrobles, Valencia), donde se localiza un interesante poblado fechado entre finales de la Edad del Bronce y época romana, así como una necrópolis de incineración correspondiente a la fase ibérica del mismo (MARTÍNEZ, 1990: 79 ss.). El hallazgo incluía un conjunto de materiales, actualmente en estudio, en su mayoría armas y útiles de hierro, en el que destacan una serie de pequeños lingotes de hierro. El conjunto, recuperado por D. Rafael Gabaldón, se encuentra actualmente depositado en el Ayuntamiento de Camporrobles (Valencia) ${ }^{1}$.

\section{2.' DESCRIPCIÓN Y ESTUDIO TIPOLÓGICO}

La falcata está partida en dos fragmentos, habiendo sido sometida a tratamiento de restauración. La hoja se encuentra seccionada transversalmente con bastante limpieza, aproximadamente en su tercio distal; la deformación que presenta a lo largo de la línea de fractura indica que se rompió mediante flexiones sucesivas hasta vencer la resistencia del material. El fragmento mayor presentaba la característica dobladura en ángulo pro-

\footnotetext{
${ }^{1}$ Queremos expresar nuestro agradecimiento a D. Rafael Gabaldón, quien nos ha proporcionado toda la información disponible relativa al hallazgo, así como al M.l. Ayuntamiento de Camporrobles por facilitarnos su estudio. Asimismo a D. Raúl Gómez, director de la Colección Museográfica de Camporrobles, donde la pieza se halla hoy expuesta, por su apoyo incondicional, incluyendo la realización de parte de la documentación fotográfica aportada, obra igualmente de $D^{a}$ $\mathrm{M}^{\mathrm{a}}$ Paz de Miguel. Finalmente, a $\mathrm{D}^{\mathrm{a}} \mathrm{M}^{\mathrm{a}}$ Dolores Sánchez de Prado, a quien se debe la realización de los dibujos a línea.
} 

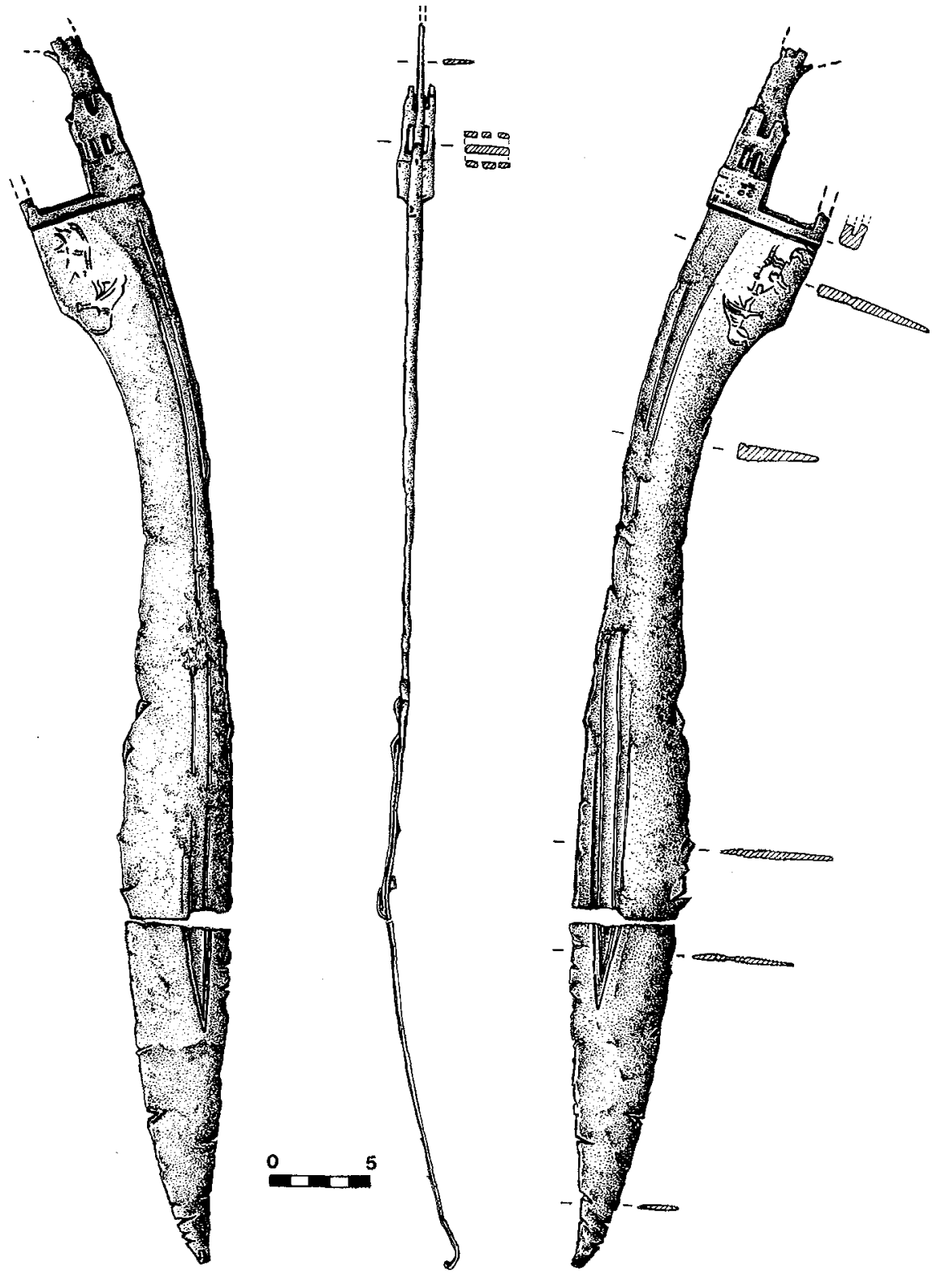

Figura 1: Falcata de la Plana de Utiel.

ducida por el esfuerzo deformante. Los fenómenos de corrosión del hierro que han actuado a lo largo de más de dos milenios han afectado a toda la superficie metálica y en particular a la sección de rotura, de manera que los dos fragmentos han perdido su exacto anclaje (fig. 2). Aprovechando la circunstancia de estar rota se ha podido efectuar una metalografía microscópica a toda la sección, que ha permitido estudiar detalladamente la estructura de la hoja.

Antes de su restauración, eran observables a simple vista los restos, muy perdidos, de decoración damasquinada de la empuñadura, por lo que como paso previo a cualquier actuación sobre la pieza se optó por radiografiarla (Lám. I), determinando de esta

forma si tal decoración podria hacerse extensible a otras partes de la misma ${ }^{2}$ (lám. II y fig. 3).

El estado de conservación de la pieza es bueno a pesar de haberse encontrado rota tanto por la empuñadura como por el tercio distal de la hoja y presentar el filo mellado, lo que, sin embargo, no ha impedido determinar las dimensiones fundamentales de la pieza (QUESADA, 1997, figs. 20-21), que en algunos

${ }^{2}$ Para tal fin se utilizó un aparato Balteau $100 \mathrm{kV}$ con venta-
na de Berilio, aplicándose una tensión de $80 \mathrm{kV}$ y un tiempo
de exposición de 2 minutos, con una película StructurixnD7 $\mathrm{Pb}$. 


\begin{tabular}{|l|c|c|c|c|c|c|c|c|c|}
\hline Variabies & $\begin{array}{c}\text { Long. } \\
\text { máx. }\end{array}$ & $\begin{array}{l}\text { Long. de } \\
\text { la hoja }\end{array}$ & $\begin{array}{l}\text { Long. del } \\
\text { filo dorsal }\end{array}$ & $\begin{array}{l}\text { Long. interior } \\
\text { empuñadura }\end{array}$ & $\begin{array}{c}\text { Anch. } \\
\text { base }\end{array}$ & $\begin{array}{c}\text { Anch. máx. } \\
\text { de la hoja }\end{array}$ & $\begin{array}{c}\text { Anch. mín. } \\
\text { de la hoja }\end{array}$ & $\begin{array}{c}\text { Ángulo } \\
\text { axial }\end{array}$ & $\begin{array}{c}\text { Peso } \\
\text { (gr) }\end{array}$ \\
\hline Dimensiones $(\mathrm{cm})$ & $\pm 64^{\prime} 6$ & \pm 56 & $\pm 25,5$ & \pm 8 & $6^{\prime} 2$ & $5^{\circ} 6$ & $3^{\prime} 6$ & $76^{\circ}$ & 667 \\
\hline
\end{tabular}

Tabla 1. Dimensiones fundamentales de la falcata.

casos hay que considerar como aproximadas (Tabla 1).

Estas dimensiones están por encima de los promedios establecidos por Quesada (1997, fig. 24) para las falcatas ibéricas, al menos por lo que se refiere a las diferentes medidas longitudinales (máxima, de la hoja y del filo dorsal). Así, la longitud media de las falcatas conocidas se sitúa en $60,2 \mathrm{~cm}$, siendo los ejemplares de mayor tamaño dos piezas de $71,5 \mathrm{~cm}$ de El Cigarralejo (QUESADA, 1997, 85). Algo similar cabe señalar respecto a la longitud de la hoja, cuya media es de $48,9 \mathrm{~cm}$, aunque se conozca un ejemplar de $61,2 \mathrm{~cm}$ procedente igualmente de El Cigarralejo (QUESADA, 1997, 85). Por su parte, el valor medio de la longitud del filo dorsal de las falcatas conocidas es de $24 \mathrm{~cm}$, a pesar de que algún ejemplar llegue a alcanzar los 34 (QUESADA, 1997, 92).

Por el contrario, la anchura basal y las anchuras máxima y mínima de la hoja de la falcata de Fuenterrobles resultan ligeramente inferiores a la media, que, respectivamente, es de $6,4,5,8$ y 3,75 (QUESADA, 1997, 86).

Estas medidas hacen que la falcata objeto de este estudio tenga una apariencia que podría calificarse de estilizada.

De otro lado, la longitud media del interior de las empuñaduras es de $8 \mathrm{~cm}$, lo que coincide con la determinada para nuestro ejemplar, a pesar de hallarse roto. No obstante, la variabilidad de esta dimensión en las falcatas ibéricas es muy pequeña, oscilando entre 7,5 y $9 \mathrm{~cm}$, excepción hecha de algún ejemplar dudoso (QUESADA, 1997, $103 \mathrm{~s}$.).

En lo referente al ángulo axial, las falcatas tienden a presentar una curvatura de $74^{\circ}$, estando la mayoría entre 65 y $83^{\circ}$, incluyéndose el ejemplar que aquí se estudia dentro de este grupo, confirmando que las hojas más largas permiten una mayor curvatura, lo que haría más eficaz el golpe cortante (QUESADA, 1997, 104 s.).

Para el estudio tipológico de la pieza analizada hemos utilizado los trabajos esenciales de E. Cuadrado (1989, 9 ss., fig. 1) y F. Quesada (1997, 83 ss., fig. 21) sobre la falcata ibérica, habiéndose optado por seguir la propuesta de este último en lo relativo a la descripción y las dimensiones fundamentales de la pieza, por más que en determinados aspectos, como la guarda basal, sigamos la tipología realizada por Cuadrado (1989, 14, fig. 5) para los ejemplares de El Cigarralejo.

La empuñadura constituye uno de los elementos principales de la falcata, siendo su forma el criterio fundamental seguido para la clasificación de estas armas (QUESADA, 1997, 100 ss.). Por desgracia, al presentar una rotura en la zona en la que la lengüeta comienza a curvarse, nuestra falcata no permite determinar la morfología de la empuñadura, correspondiendo, por tanto, al tipo C de Quesada $(1997,102)$, que incluye las empuñaduras rotas o indeterminadas, aunque ello no impida calcular, como hemos dicho, las dimensiones completas de la pieza.

La estructura de la empuñadura puede considerarse como excepcional, ya que parte de las cachas ofrecen estructura metálica mediante el ensamblaje de varias piezas, perdidas en parte en nuestra falcata, frente a lo que se considera como habitual en este tipo de armas, en las que a la lámina de metal que

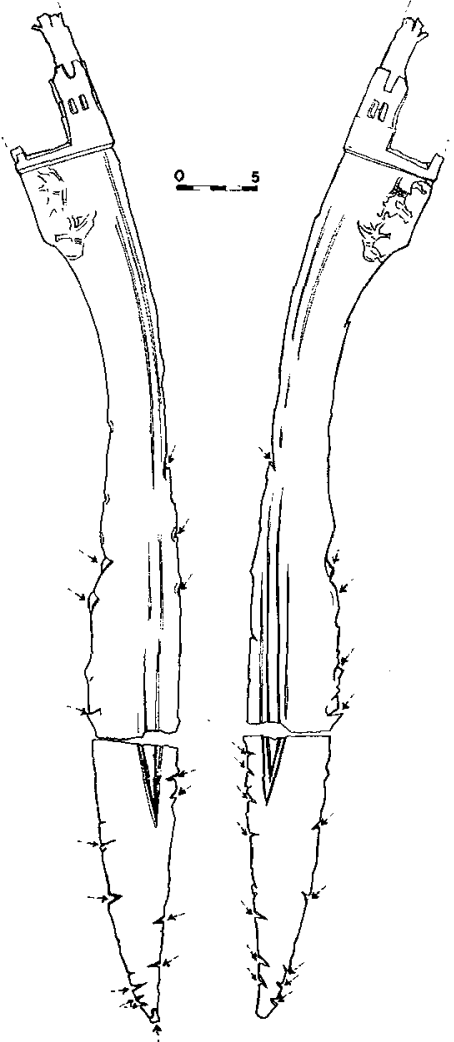

Figura 2: Esquema de cortes y melladuras documentados en los filos de la pieza. 
forma el alma de la empuñadura se remachan las cachas de hueso o madera (QUESADA, 1997, 100).

La guarda basal, cerrada y formada por dos piezas simétricas, presenta el extremo del lado dorsal ensanchado, creando un espacio rectangular o "cartela" que ocupa el arranque de la empuñadura y sobre el que se desarrollará la decoración, clasificándose dentro del tipo A1 de Cuadrado (1989, 14, fig. 5) o "de cartela grande". A cada una de estas piezas se le adosan por el extremo dorsal otras dos, caladas y también simétricas, que formarían parte de las cachas metálicas de la empuñadura, hasta alcanzar su zona mesial. Todas ellas irían remachadas a la lengüeta, que resulta solidaria con la hoja, no apreciándose a simple vista evidencias de tales remaches para las cachas. Aun así, la radiografía permite documentar la existencia de una perforación circular en la lá- mina que forma el alma de la empuñadura (fig. $3)$, que cabe relacionar con la existencia de uno de estos remaches. Las junturas de unión de las piezas no están claras, seguramente al haber sido limadas y pulidas hasta conseguir una superficie regular sobre la que realizar la ornamentación (PRATS et alii, 1996, 150). El extremo de la guarda correspondiente al lado del filo presenta un saliente o "apéndice", actualmente fracturado, que parece sugerir la existencia de una barra maciza a modo de guarda lateral.

La estructura descrita resulta semejante a la identificada en una falcata de Almedinilla (Córdoba) (NIETO y ESCALERA, 1970), que debió estar restringida a ejemplares muy ricos (QUESADA, 1997, 100).

Por lo que a la hoja se refiere, hay que hacer mención a diferentes aspectos, destacando la presencia de acanaladuras, ele-
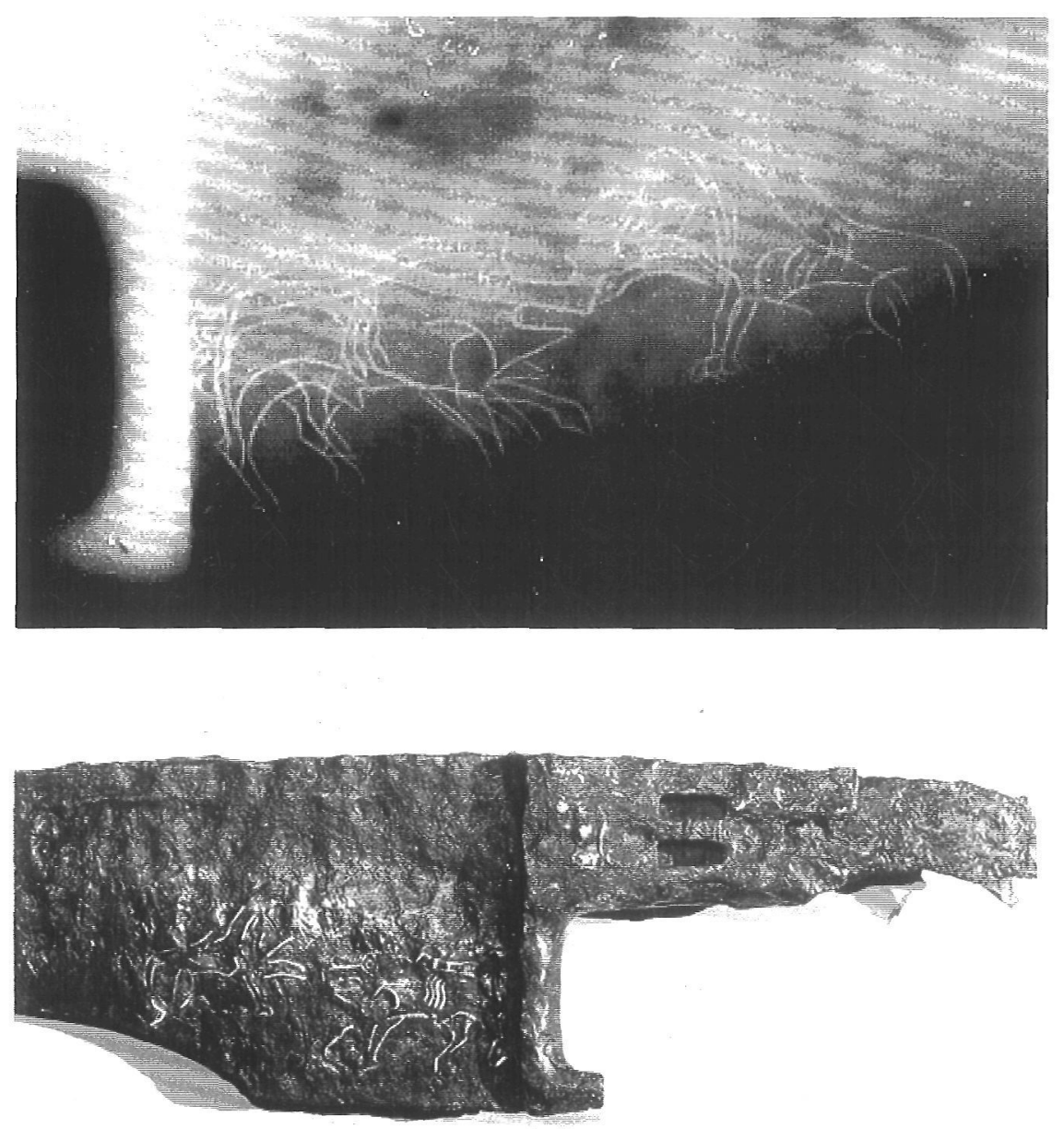

Lámina I. 1, Radiografía de la falcata, con la superposición de las escenas reproducidas en ambos lados de la hoja. 2, Detalle de la decoración del lado izquierdo, la mejor conservada, de la falcata (foto R. Gómez). 
mento característico de la inmensa mayoría de las falcatas ibéricas (QUESADA, 1997, 93 ss.). En el caso que nos ocupa, las acanaladuras, siguiendo la norma observada en este tipo de armas (QUESADA, 1997, 93), arrancan desde la base de la empuñadura y se extinguen a unos $14 \mathrm{~cm}$ de la punta, siguiendo un trazado paralelo entre sí y al filo de la hoja, abriéndose ligeramente al inicio del filo dorsal mientras que junto a la empuñadura son divergentes (tipo 1 de Quesada). Se trata de dos haces de otros tantos surcos, mejor conservados en el tercio distal de la falcata, estrechos y con fondo en $U$, aun cuando debido al estado de deterioro de la pieza no sean visibles en todo su recorrido.

Tanto el filo principal como el dorsal presentan, a veces, evidencias de melladuras simples, aunque en ocasiones la pieza aparezca claramente cortada, lo que cabría relacionar con una inutilización intencional del arma, con la que sin duda habría que asociar la fractura observada en el tercio distal de la hoja que, como se ha señalado, se produjo mediante flexiones sucesivas hasta conseguir la rotura de la pieza (fig. 2). Tales marcas se hacen más frecuentes en la zona de la punta, que aparece incluso doblada sobre sí misma.

\section{DECORACIÓN}

Además de la forma de la empuñadura que, como ya se ha dicho, no se ha conservado, o de la propia presencia de acanaladuras, elementos ambos que suman a su carácter funcional otro eminentemente decorativo, la falcata presenta decoración damasquinada en plata, localizada en la empuñadura, en concreto en la cartela de la guarda basal y sobre la pieza rectangular que forma parte de la empuñadura metálica, así como en la zona de la hoja en contacto con la empuñadura y en el dorso de la pieza (en el sector correspondiente a la empuñadura y a la parte superior de la hoja).

La decoración de la empuñadura (lám. I y fig. 3) se encuentra prácticamente perdida, aunque en la guarda basal queden restos de lo que puede interpretarse como un friso, posiblemente de motivos geométricos o vegetales de tipo palmeta (QUESADA, 1997, fig. 66, 22-24), y en el dorso únicamente se
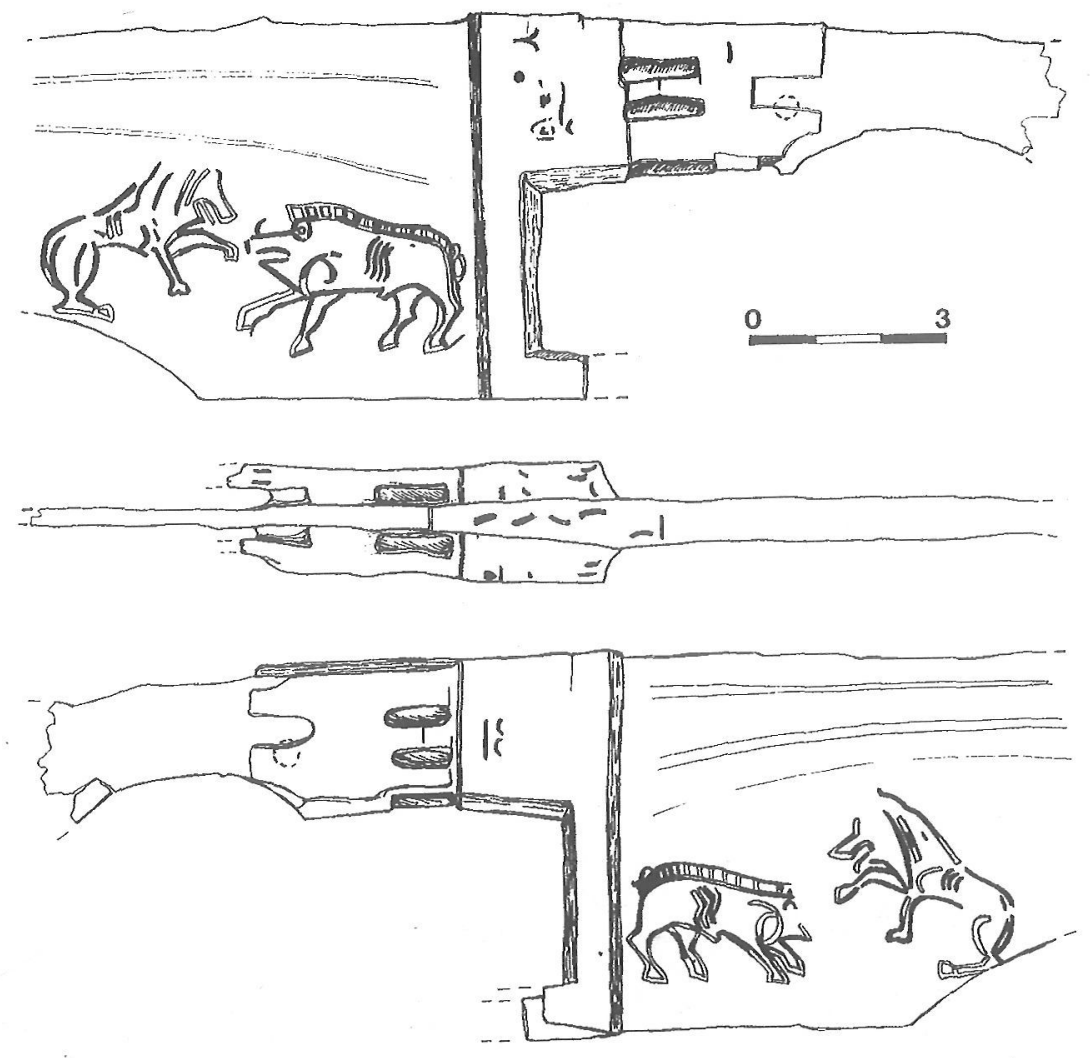

Figura 3. Reconstrucción de la escena principal a partir de la radiografía y de la propia pieza (en trazo grueso negro) una vez restaurada, con la localización de los restos de decoración identificados. 

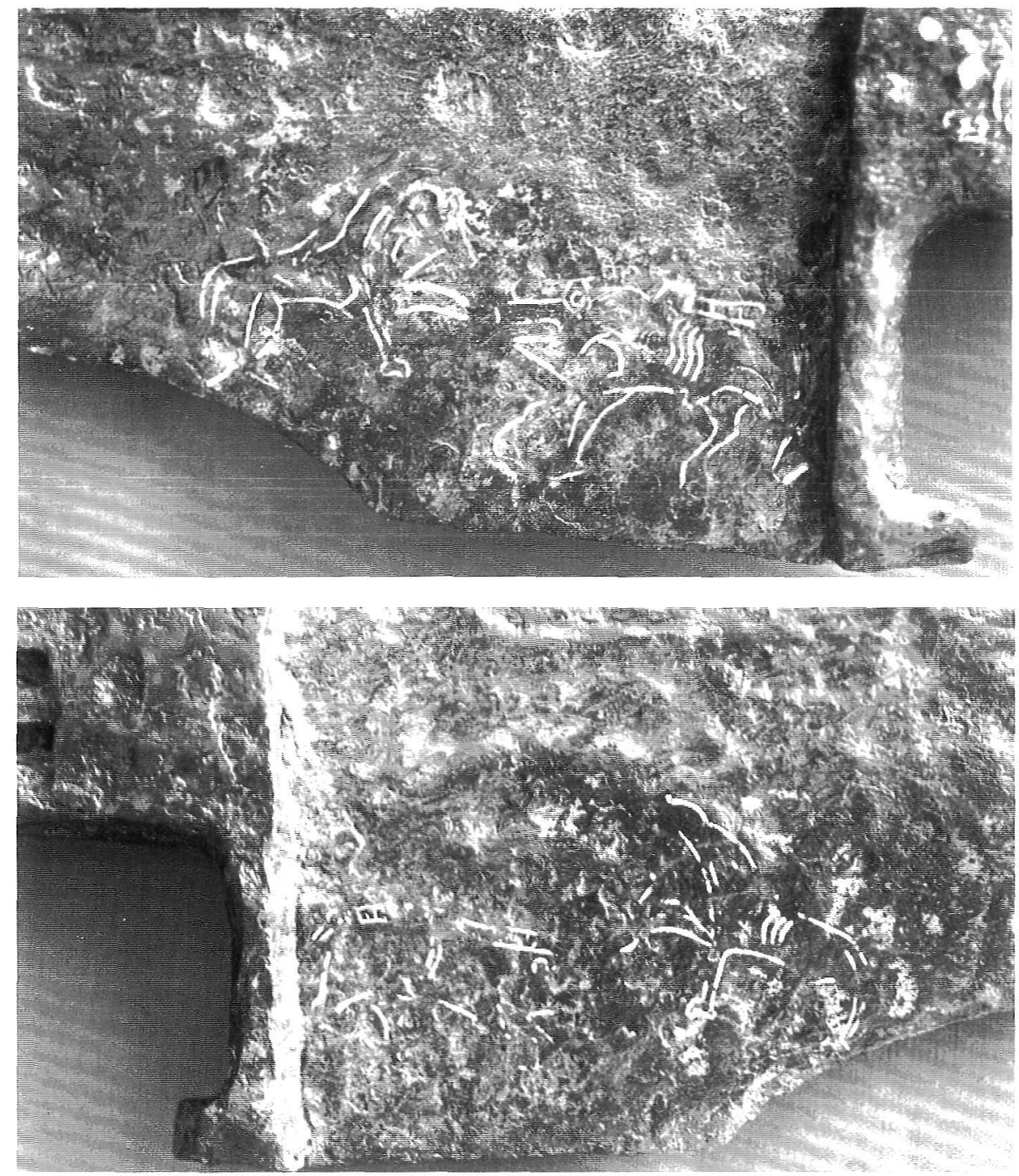

Lámina II. Detalle de la escena principal, reproducida en ambos lados de la hoja $(E 1: 1,5)$ (fotos $M^{a}$ Paz de Miguel).

observe la presencia de restos de hilos de plata en la empuñadura y en la parte de la hoja más próxima a ella.

Mejor conservada está la decoración en el amplio espacio donde la hoja se une a la empuñadura. Allí, en lo que constituye el centro de la decoración de la falcata, se han representado dos animales, un jabalí y un felino, en una escena de lucha, reproducida en ambos lados de la pieza (láms. I y II; fig. 3). El jabalí, en general mejor conservado que el felino, se encuentra en la zona interior, mirando hacia fuera. Se ha representado en movimiento, con las patas delanteras ligeramente adelantadas. Una serie de líneas onduladas representan el costillar del animal, que presenta la boca abierta, con las defensas marcadas, el ojo circular y el pelaje de la espalda erizado a modo de cresta, reflejando la actitud agresiva del animal. Por su parte, el felino, posiblemente un león por las líneas que parecen indicar la melena del animal, se halla en la parte exterior de la composición, mirando hacia dentro. Se apoya sobre sus cuartos traseros, presentando la pata derecha levantada en actitud de ataque. Tiene la boca abierta, mostrando con claridad la lengua.

Una representación semejante, si bien más compleja, está documentada en un ejemplar conservado en el SIP de Valencia, de procedencia dudosa (ARANEGUI, 1992). La escena, menos "realista" que la reproducida en nuestra falcata, presenta a un león en posición de ataque enfrentado a un jabalí "agazapado", sobre los que se posan cuatro aves (ARANEGUI, 1992, 321). Los dos animales principales ocupan la posición inversa a la registrada en el ejemplar de la Plana de Utiel, 
esto es, el león en la zona interna y el jabalí en la externa. El enfrentamiento entre ambos animales está documentado, igualmente, en la pátera de Tivissa, aunque en este caso el león se localice directamente sobre el jabalí (BLÁZQUEZ, 1977, 224, fig. 74).

Si las representaciones de felinos, sobre diferentes tipos de soportes, son habituales en el arte ibérico, pudiéndose defender un origen claramente mediterráneo para los mismos (CHAPA, 1985, 123 ss.), algo parecido puede señalarse respecto a las de jabalíes (CHAPA, 1985, 201 ss.), pero, a diferencia de aquéllos, éstos resultan especialmente habituales entre los pueblos célticos, tanto peninsulares (CERDEÑO, 1994) como del otro lado de los Pirineos (GREEN, 1992: 44 s.). Dichos animales simbolizan aspectos como la ferocidad, la fortaleza o el valor, y así aparecen reflejados en la obra de Homero (Iliada V, 7823) o Estrabón (IV, 4, 3); pueden tener, igualmente, un carácter funerario (BLÁZQUEZ, 1977, 227; Idem, 1983, 34, 150, 156 ss. y 190).

Sin duda la presencia de decoración debe verse como un valor añadido al de la propia posesión de la falcata, que, en cualquier caso, solamente debía estar al alcance de un sector restringido de la población. Además de ser un símbolo de estatus, podría interpretarse, de acuerdo con Quesada $(1997,117)$, como un elemento de identificación personal, en especial si se trata de piezas excepcionales como la que aquí se presenta. Junto a ello, no habría que desestimar su valor como amuleto protector, constatado por la propia elección de la escena principal. En este sentido, se ha señalado que tales armas, que cabría considerar como "de parada", quizás tendrían un fuerte contenido simbólico-religioso, pudiéndose aventurar que hubieran sido fabricadas, incluso, para tal fin (QUESADA, 1997, 117). Debe tenerse en cuenta, también, que, en aquellos casos en los que se ha podido determinar el origen de las falcatas damasquinadas, siempre corresponden a contextos funerarios, excepción hecha del ejemplar de la Plana de Utiel, para el que cabe plantear una interpretación diferente. El hecho de que se encuentre inutilizada intencionadamente desde antiguo nos lleva a pensar que pudiera proceder de un cementerio, aunque el material asociado -armas o fragmentos de ellas, útiles y, sobre todo, lingotes-, y la completa ausencia de cerámica o de cualquier otro resto habitual en este tipo de yacimientos, permite su interpretación como un posible depósito de herrero.
Una interpretación diferente ha sido propuesta por Aranegui $(1992,325)$ para la pieza del SIP, que podría tratarse de un trofeo otorgado al vencedor de un juego gladiatorio (vid., no obstante, QUESADA, 1997, 120). Esta pieza presenta en el dorso una inscripción ibérica grabada a buril, en la que aparece, además de un antropónimo, el término ekiar, que estaría haciendo referencia, según de $\mathrm{Hoz}$ (1992, 335 ss.), bien al artesano -"hecho por"o quizás al beneficiario -"hecho para"-, aunque también podría tratarse de algún tipo de título. Aunque el estudio paleográfico no permite fechar la inscripción (DE HOZ, 1992, 331), para Quesada $(1997,123)$ la falcata no sería anterior al siglo III a.C.

Por lo que respecta a la cronología del resto de las falcatas decoradas, la mayor parte de ellas se fechan en el siglo IV a.C., conociéndose, sin embargo, ejemplares datados en los siglos III y II a.C. (QUESADA, 1997, 116).

Diremos, por último, que la distribución geográfica de las falcatas damasquinadas (fig. 4) se concentra en el Sureste y la Alta Andalucia, con un único hallazgo en el área extremeña (QUESADA, 1997, 116, fig. 64); el ejemplar de la Plana de Utiel vendría a otorgar un mayor peso específico a los hallazgos procedentes del Levante peninsular, hasta la fecha representados por las piezas de las necrópolis alicantinas de La Serreta (MOLTÓ y REIG 1996; PRATS et alii, 1996) y La Albufereta (RUBIO, 1992, figs. 38, 40, 44 y 54). Sobre este punto, no habría que dejar de lado que el ejemplar del SIP, con el que la pieza aquí

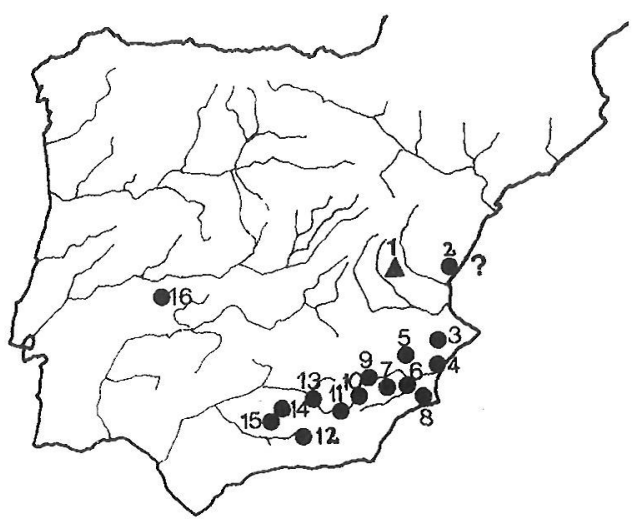

Figura 4. Mapa de distribución de las falcatas con decoración damasquinada (según Quesada 1997, completado): 1. Fuenterrobles; 2. Sagunto (?); 3. La Serreta; 4. La Albufereta; 5. Coimbra del Barranco Ancho; 6. Cabecico del Tesoro; 7. Cigarralejo; 8. Los Nietos; 9. Carranza; 10. Galera; 11. Baza; 12. Illora; 13. Castellones de Ceal; 14. Torviscales; 15 Almedinilla; 16. Dehesa del Rosarito. (1-2, Valencia; 3-4, Alicante; 5-8, Murcia; 9-12, Granada; 13, Jaén; 14-15, Córdoba; 16, Cáceres). 
presentada guarda similitudes en su temática decorativa, fue adquirido como procedente de Sagunto o su entorno, a pesar de que los datos contradictorios en relación con su procedencia aconsejaran mantener una duda razonable sobre el particular (ARANEGUI, 1992, 319, nota 2).

\section{ESTUDIO TECNOLÓGICO}

Uno de los problemas que plantea el estudio de metales antiguos es el derivado de la corrosión, por los cambios morfológicos que ocasiona. El hierro es un metal situado en una posición intermedia en la serie galvánica, con un potencial normal de oxidación a $25^{\circ} \mathrm{C}$ de 0 '440 voltios. Se oxida, pues, con cierta facilidad. Los productos de esta oxidación, lo que familiarmente llamamos capa de herrumbre, están formados en principio por óxido que, en presencia de humedad pasa a hidróxido y otros complejos de la familia. La herrumbre de un hierro enterrado es mucho más compleja que el óxido-hidróxido. La presencia de cloruros en el suelo (sal común y otros compuestos de cloro), muy frecuente, también ataca al hierro formando el cloruro correspondiente. Todas estas substancias constituyen una pátina mecánica y químicamente inestable sobre la que actúan fenómenos de disolución en presencia de humedad en el terreno envolvente (tiñendo el suelo con manchas ferruginosas), al tiempo que la formación de nuevos productos de corrosión en el frente de ataque empuja a los ya formados haciendo que se desprendan en forma de escamas.

En el caso del hierro en proceso de oxidación, la pérdida de substancia y la deformación volumétrica respecto del objeto original son importantes y deben ser tenidas en cuenta no sólo por lo que afectan a la morfología actual de la espada sino también a la hora de interpretar su estructura interna, dada la imposibilidad de determinar la posición de la epidermis o superficie inicial de la masa metálica.

En los materiales metálicos ibéricos debemos tomar en consideración otras circunstancias que derivan de los rituales: la acción del fuego de la pira de cremación del cadáver (cuando se trata de materiales recuperados en necrópolis) y la inutilización ritual de armas $u$ otros objetos de uso personal. El primer elemento, el fuego, puede ocasionar cambios microestructurales en los metales si su acción es lo suficientemente prolongada; en el caso del hierro se concretarían en fenómenos de recristalización (aumento de la forma y del tamaño de grano del material) y en el acero habría, además, la posibilidad de descarburación y/o re-disolución en sólido de la cementita (componente fundamental del acero). En cualquier caso, las cualidades mecánicas del material podrían cambiar drásticamente.

En el caso de la falcata que nos ocupa, su contexto arqueológico no es claro pues procede de un hallazgo casual, aunque, como ha quedado expuesto, existen argumentos suficientes para desestimar que pudiera proceder de una necrópolis.

Iniciaremos el estudio tecnológico desde el filo hacia el dorso, en una sección completa de la hoja. El filo está formado por ferrita prácticamente pura (hierro dulce). La metalografía (lám. III) revela la presencia de granos de tamaño irregular, algunos de los cuales se hallan surcados por líneas de maclado (series de líneas paralelas) debidas a una ligera deformación del metal en frío, quizás un golpe para cortar un material de cierta dureza.

Cerca del filo, a unos pocos milímetros, aparece en uno de los flancos de la hoja el nacimiento de una segunda lámina metálica de estructura diferente. En la lámina IV puede observarse el arranque de esta lámina, ligeramente despegada en su inicio. El espesor que se conserva apenas supera los $0,2 \mathrm{~mm}$. Vista a mayores aumentos (lám. V) se identifica claramente un acero al carbono, con una proporción aproximada de $0,3-0,4 \% \mathrm{C}$, formado por perlita laminar dispuesta entre los granos blancos de ferrita. La zona de contacto entre la lámina ferrítica y la acerada muestra claramente el cambio de textura y de tamaño de grano (lám. VI). Siguiendo en el corte metalográfico el recorrido de la unión entre ambas láminas se aprecia en algunas zonas la presencia de escorias ocluidas que marcan precisamente el límite de contacto de las superficies (lám. VII).

Hacia la mitad de la hoja se pierde la lámina acerada y la única estructura visible es la de la lámina de ferrita. Aquí, donde el espesor es mayor, se aprecian numerosas fibras de escoria seccionadas, de forma circular o alentejada, entre los grandes granos de ferrita (lám. VIII). Estas escorias atrapadas en el metal son características de los hierros antiguos. Forman fibras alargadas por el tratamiento de forja en caliente (aquí las estamos viendo en sección transversal), y cuando no son excesivamente numerosas como en este caso, mejoran las propiedades mecánicas del hierro dulce. 


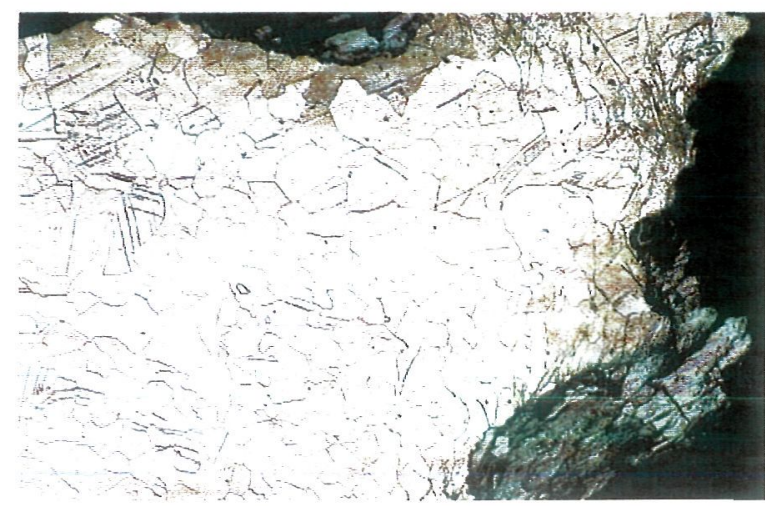

Lámina III. Sección metalográfica correspondiente al filo. Estructura ferrítica de granos equiaxiales. En el ángulo superior derecho se observan algunos granos maclados por deformación en frío. El ataque de la corrosión forma un frente irregular de picaduras. Ataque con nital. 100x

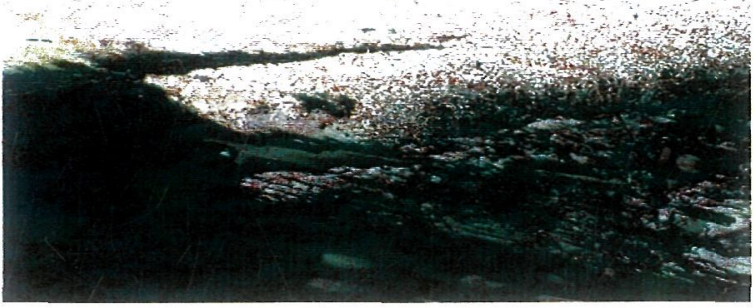

Lámina IV. Zona de arranque de la lámina carburada, cerca del filo. Obsérvese la diferencia estructural de ambas láminas. Ataque con nital. 50x.

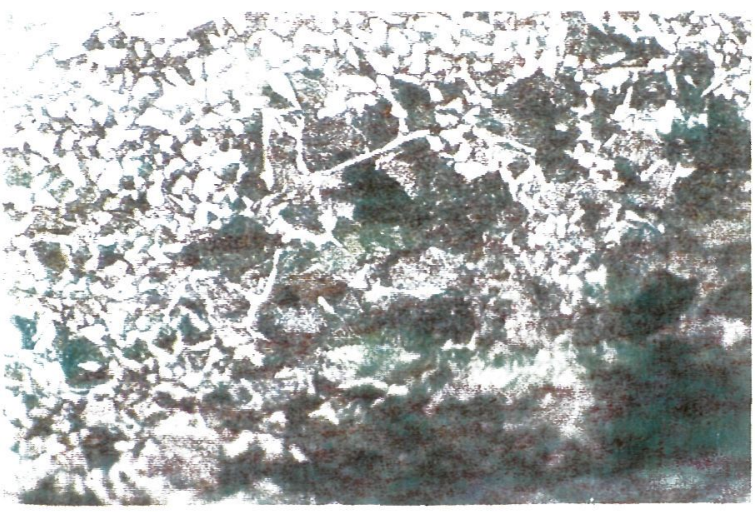

Lámina V. Microestructura de la lámina de acero: perlita laminar en una matriz ferrítica. Ataque con nital. 500x.

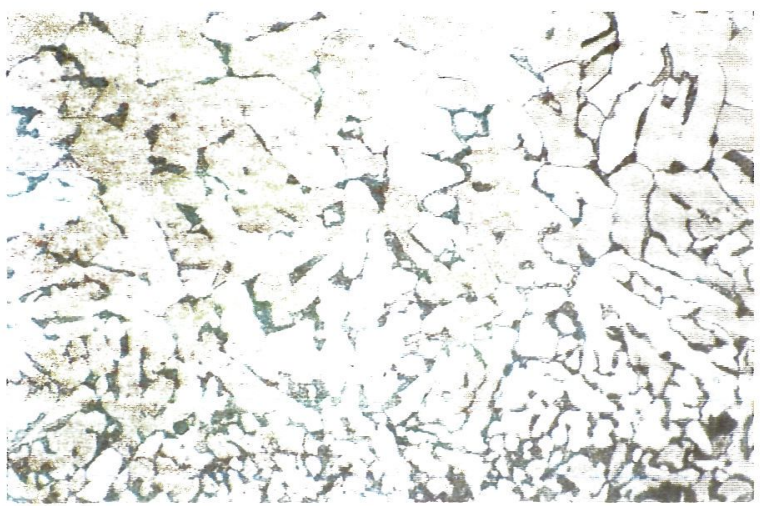

Lámina VI. Zona de contacto entre la lámina interior del hierro dulce (parte superior de la imagen) y la exterior acerada (parte inferior). Obsérvese las diferencias de tamaño de grano y de carburación. Se aprecia un cierto grado de interdifusión en sólido de la perlita. Ataque con nital. 500x.

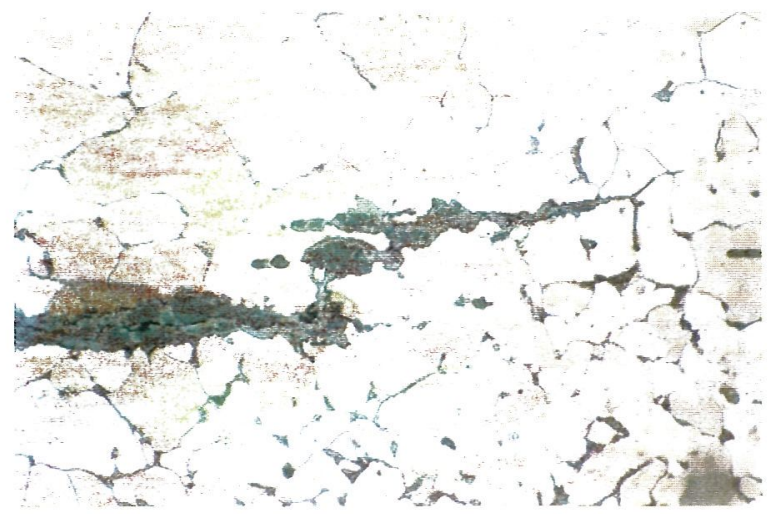

Lámina VII. Línea de soldadura de las dos láminas, abierta y ocupada por productos de corrosión del hierro. Nótese la gran diferencia de tamaño de grano de ambas láminas. Ataque con nital. 500x.

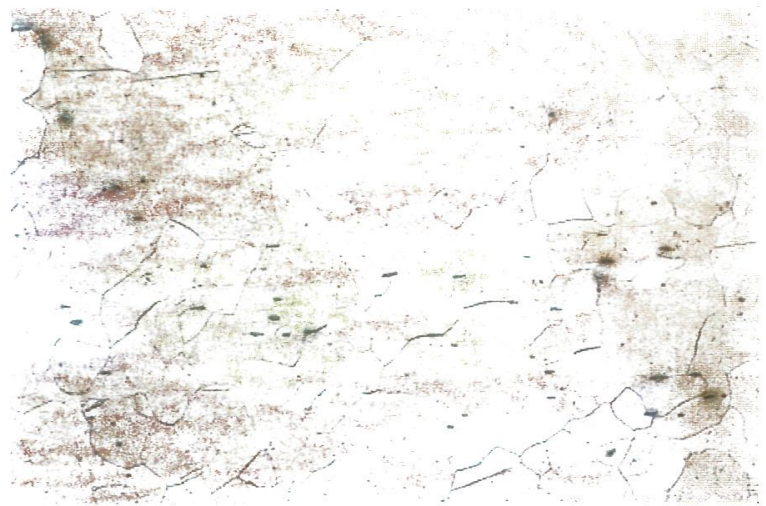

Lámina VIII. Estructura metalográfica de la lámina de hierro dulce hacia la mitad de la sección de la hoja. Los puntos oscuros son fibras de escoria cortadas. Ataque con nital. $200 x$. 


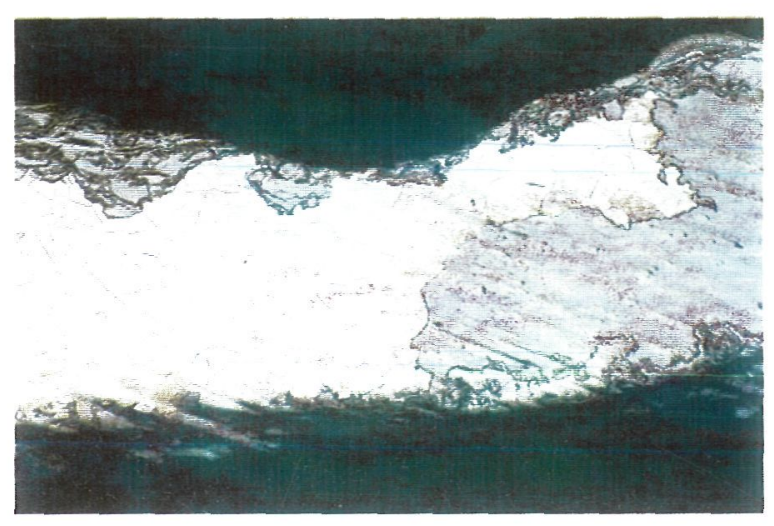

Lámina IX. Adelgazamiento de la hoja en la zona de los surcos o acanaladuras. No se aprecia deformación en frío del metal. Ataque con nital. 100x.

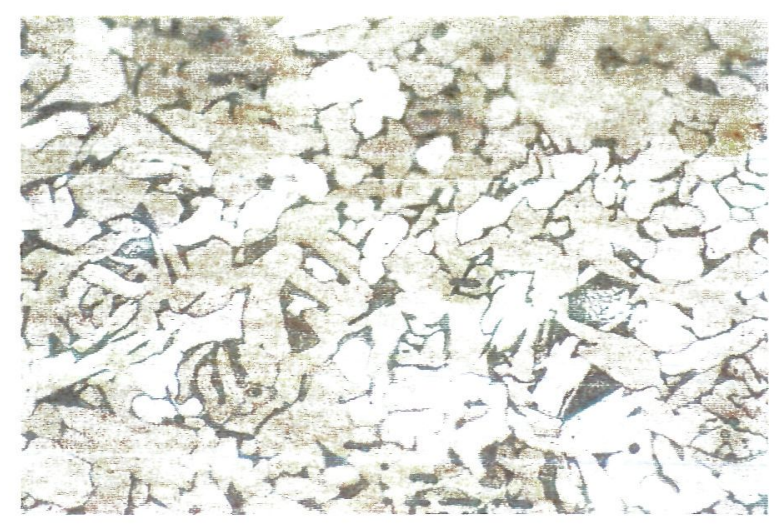

Lámina XI. Estructura acerada de la varilla del contrafilo. Ferrita más perlita laminar. Ataque con nital. 500x.

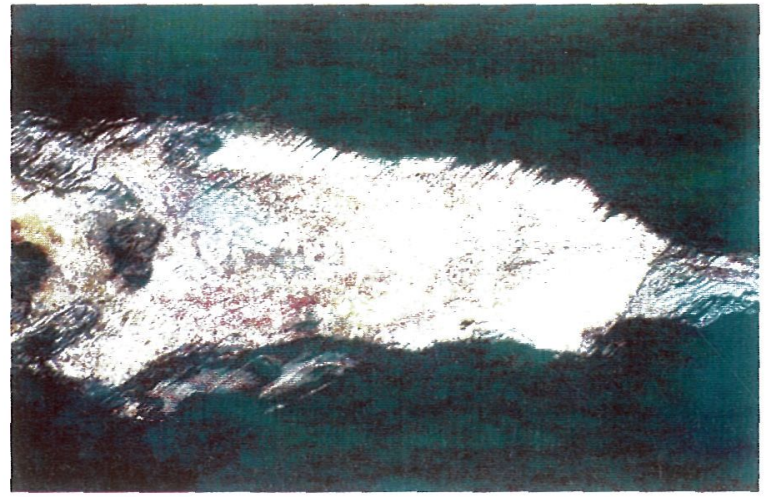

Lámina X. Sección de la varilla que constituye el contrafilo de la hoja. Ataque con nital. 25x.

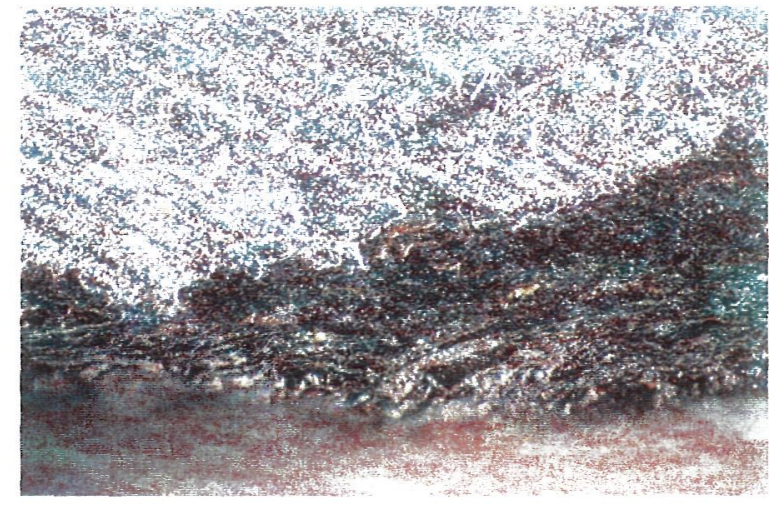

Lámina XII. Sección de la hoja de la falcata mostrando la estructura laminar de la capa de productos de corrosión superficial (parte inferior de la imagen). lluminación de campo oscuro. 200x.

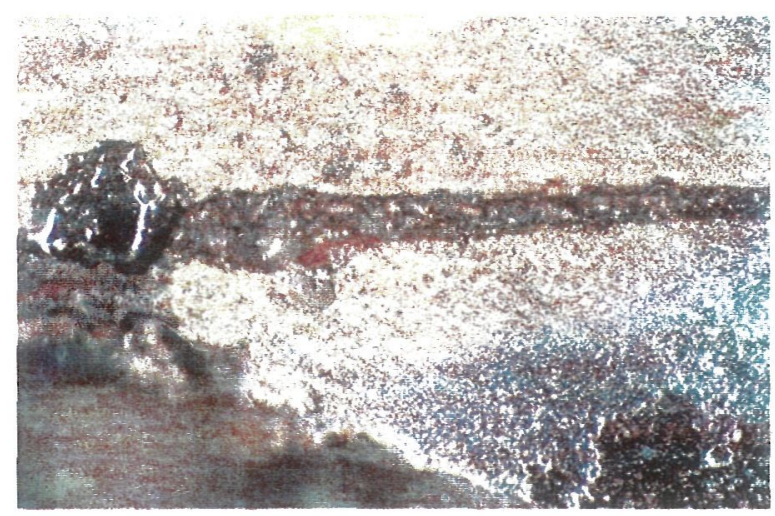

Lámina XIII. Detalle de una fisura en la hoja de la falcata, rellena con productos de corrosión. Iluminación de campo oscuro. 200x. 
La hoja de la espada presenta unos sur$\cos$ o acanaladuras longitudinales. La metalografía en sección no permite observar deformación mecánica alguna en el metal. La lámina IX muestra los granos de ferrita bien conformados en las partes correspondientes al fondo del surco. Esto puede interpretarse de dos maneras: a) que se grabaron con el metal en caliente, con algún tipo de matriz a propúsito, y que después de grabarlos la hoja fue de nuevo introducida en la fragua, como consecuencia de esta operación o de otras necesarias; posteriormente, ya con el metal frío, se debie. ron repasar con las herramientas adecuadas para darles la forma definitiva, b) que son tra. zos de buril, arrancando poco a poco el metal del surco sin llegar a deformarlo.

El dorso de la hoja está constituido por una varilla de acero dispuesta longitudinalmente sobre el plano de la hoja, formando una estructura de refuerzo. En la lámina $X$ puede apreciarse el montaje: a la izquierda se distingue la línea de unión curva de la hoja y su dorso, muy engrosada por productos de corrosión. La lámina $X I$ es un detalle de la microestructura de este acero, con aproximadamente $0,2 \%$ de carbono en forma de perlita laminar dispuesta entre los granos blancos de ferrita. Si la comparamos con las láminas $\mathrm{VI}$ y VII comprobaremos que ni el tamaño de grano ni el grado de carburación coinciden con los de la lámina central, argumentos que sirven para confirmar que se trata de un material distinto.

Así, pues, esta falcata, por lo que se refiere a la hoja, es una estructura compleja de láminas apiladas, soldadas a la calda. Tenemos, por un lado, la hoja propiamente dicha constituida por una gruesa lámina de hierro dulce flanqueada por otra más delgada de acero. Es probable que originalmente fueran dos las láminas de acero, formando una especie de emparedado, y que una haya sido corroída completamente en la zona observada. El dor so o contrafilo es otra estructura diferente compuesta por una varilla que se dispone a lo lar. go de la hoja. No se aprecian signos de que el metal fuera templado. Todo parece indicar que tras el último tratamiento de forja en caliente fue dejado enfriar lentamente fuera de la fragua hasta la temperatura ambiente.

Uno de los estudios más completos de una falcata ibérica llevados a cabo hasta el momento es el efectuado por Nieto y Escalera (1970) al ejemplar de Almedinilla conservado en el Museo Arqueológico Nacional. En este caso, la hoja está compuesta por tres láminas empaquetadas que llegan hasta el contrafilo; siendo la intermedia acerada y las laterales de hierro poco o nada carburado ${ }^{3}$. Estas láminas laterales no cubren toda la hoja, sino que terminan a unos centímetros del filo. Tal disposición es precisamente la inversa de la que apreciamos en la falcata aquí analizada y tiene la gran ventaja de que el filo siempre correspon. de a la lámina de acero y, por lo tanto, conser. va mejor las propiedades de corte, a pesar de que el acero no se templó 4 .

En el Museo Pitt Rivers de Oxford se con. serva otra falcata procedente de Almedinilla, estudiada por H.H. Coghlan (1956-57). Aunque el trabajo original no ha podido ser consultado, este mismo autor lo resume (COGHLAN, 197\%, 87-88) diciendo que está confeccionada con hierro forjado de inferior calidad y consiste sólo en "unas pocas láminas empaquetadas que contienen muchos filamentos de escoria atrapados". El contenido de carbono oscila entre 0,04 y $0,1 \%$, es decir, hierro dulce y acero suave. No fue sometida a ningún tratamiento de carburación ni de templado.

Un tercer ejemplar de espada afalcatada procede de la localidad etrusca de Vetulonia (COGHLAN, 1977, 88). Su estructura es más compleja que la de las falcatas españolas y está formada por dos láminas de acero y tres de hierro dulce, alternadas, que permiten obtener un buen material con la adecuada dureza y que, no obstante, resiste la flexión sin romperse. Tampoco este ejemplar fue sometido a tratamientos térmicos de endurecimiento.

Un par de hojas de cuchillo inglesas, pre. romanas, fueron metalografiadas por Tylecote y Gilmour (1986). Una de ellas está compuesta por una sola lámina, carburada por una cara en toda su superficie, sin templar. La otra, forma un paquete de láminas aceradas y templa. das.

\footnotetext{
${ }^{3}$ En las láminas de hierro dulce se aprecia carburación superficial que los autores atribuyen a un proceso de cementación final de la hoja (NIETO y ESCALERA, 1970 , 29). La lámina de acero carburado contiene alrededor de un $0,4 \% \mathrm{C}$, según se aprecia en la figura 11 del mencionado trabajo.

${ }^{4}$ Una estructura semejante presentaría la falcata de la tumba 53 de La Serreta (Alcoy, Alicante), con un nervio central longitudinal formado por diversas capas metálicas, de mayor grosor que las de las dos laterales, mientras que la punta constaría, en cambio, de dos láminas superpuestas; lamentablemente, la pieza está muy afectada y no permite determinar diferencias en la composición del hierro según las zonas (PRATS et alii, 1996, 149).
} 
A la vista de este material podríamos concluir que la calidad de las falcatas es irregular, incluso en ejemplares procedentes de un mismo yacimiento, como es el caso de las espadas de Almedinilla. En comparación con la de Vetulonia, la estructura de las dos ibéricas es más simple. Pero todas coinciden técnicamente en dos aspectos: son hojas a base de láminas empaquetadas y no recibieron tratamientos térmicos de templado. La espada aquí estudiada presenta la variante estructural del contrafilo, que no se documenta en los otros casos.

A pesar de la finura de la decoración damasquinada con hilo de plata que realza el valor de la pieza, nuestra falcata debía resultar un arma poco eficaz. El hecho de que en la zona observada sólo se aprecie una lámina carburada (y no en toda su extensión), no demasiado espesa, aun suponiendo que se haya perdido su simétrica (al menos en la sección correspondiente a la metalografía), compone una estructura endeble. Aunque no podamos valorar las pérdidas por corrosión, no debe ser mucha la mengua de espesor de la hoja puesto que se han conservado las ataujías de la superficie. Puesta en servicio, la hoja debía doblarse con facilidad al ser en su mayor parte de hierro dulce.

Tampoco podria aducirse que el fuego de la pira funeraria (suponiendo que hubiera actuado sobre ella y que la pieza procediera de un contexo funerario, lo que no parece probable) ha provocado la descarburación superficial, pues precisamente la parte carburada se conserva en el área más externa de la hoja.

\section{RESTAURACIÓN}

La superficie de la pieza presentaba una capa de productos de corrosión cubriendo toda la superficie, de un espesor variable entre $1 \mathrm{y}$ $2 \mathrm{~mm}$ en la zona metalografiada, donde se apreciaba también una lámina interna de metal sano de un espesor máximo de $5 \mathrm{~mm}$. La lámina XII muestra la estructura laminar de los óxidos e hidróxidos de hierro, con fases intercaladas pulverulentas, de color marrón más claro.

Además de la corrosión superficial existen penetraciones hacia el interior del núcleo siguiendo el recorrido de las fisuras del material (lám. XIII). Esta forma de agresión es muy peligrosa para la conservación de la pieza dada la dificultad de ser pasivada actuando desde fuera y demanda medidas de conservación preventiva para detener su progreso.
Sobre la capa de corrosión se encontraban depositados materiales terrosos adheridos fuertemente tras los años de enterramiento en el suelo, así como capas carbonatadas de color blanco grisáceo características de los lechos calizos, limonitizadas hacia el interior.

También debemos mencionar la formación de ampollas por condensaciones locales de humedad que, al ser atacadas con un instrumento punzante, mostraban su interior mojado y saturado de óxido ferroso. Estas lesiones se han producido después de ser desenterrada la falcata, por un exceso de humedad ambiental.

Los estudios radiográficos habian revelado la existencia de decoración damasquinada con hilo de plata figurando animales, en ambas caras de la hoja de la espada, totalmente irreconocibles a simple vista. Previsiblemente, estas decoraciones se habrían movido de su posición original sobre el metal sano y estarían apoyadas sobre la capa de óxidos. Esto hacía inviable la aplicación de un tratamiento de reducción electrolítica o electroquímica por el riesgo de que, al eliminar los óxidos, el damasquinado quedara descalzado. Se optó, pues, por la limpieza por medios mecánicos, con punzones, bisturíes y distintos tipos de fresa accionados por micromotor.

La limpieza comenzó en las zonas donde se encontraban las decoraciones, cuya situación exacta conocíamos con toda precisión por las radiografías. Luego continuó con el resto de la pieza. En algunas zonas se hicieron pruebas con ácido oxálico al $10 \%$ en agua desmineralizada para reblandecer la corrosión.

Tras ser lavada la pieza con una mezcla al $50 \%$ de acetona y alcohol para eliminar los restos de ácido oxálico, se introdujo en un baño de ácido fosfórico al $20 \%$ en agua desmineralizada, previamente calentada con infrarrojos, para procurar una capa de pasivado.

Una vez seca, se impregnó con una capa protectora y consolidante de Paraloid B-72 al $5 \%$ en disolvente orgánico.

Como se ha comentado al principio, la falcata estaba partida en dos. Se hubieran podido unir las partes con alguna resina inerte maquillando la unión, pero puesto que no encajaban exactamente se optó por no unirlas, recomendando un soporte adecuado para su exposición en el museo.

\section{BIBLIOGRAFIA}

ARANEGUI, C. y DE HOZ, J., 1992: «Una falcata decorada con inscripción ibérica. Juegos gladiatorios y venationes. Estudio epigráfico", Estudios de Arqueología Ibérica y 
romana. Homenaje a Enrique Pla Ballester, (S.I.P., Trabajos Varios $n^{\circ} 89$ ), Valencia, 319-344.

BLÁZQUEZ, J.M., 1977: Imagen y Mito. Estudios sobre religiones mediterráneas e ibéricas, Madrid.

BLÁZQUEZ, J.M., 1983: Primitivas religiones ibéricas. Tomo II. Religiones prerromanas, Madrid.

CERDEÑO, ML. y CABANES, E., 1994: «El simbolismo del jabalí en el ámbito celta peninsular», Trabajos de Prehistoria, $51, n^{\circ} 2,103-119$.

COGHLAN, H.H., 1956-57: "Etruscan and Spanish swords of iron". Sibrium, 3, 167-174.

COGHLAN, H.H., 1977: Notes on Prehistoric and Early Iron in the Old World, $2^{\text {nd }} \mathrm{Ed}$, (Pitt Rivers Museum. Occasional Papers on Technology, 8. University of Oxford), Oxford.

CUADRADO, E., 1989: La panoplia ibérica de «El Cigarralejo" (Mula, Murcia), Murcia.

CHAPA, T., 1985: La escultura ibérica zoomorfa, Madrid.

DE HOZ, J., 1992: «Estudio epigráfico», en ARANEGUI, C. y DE HOZ, J., 1992: «Una falcata decorada con inscripción ibérica. Juegos gladiatorios y venationes. Estudio epigráfico", Estudios de Arqueología lbérica y romana. Homenaje a Enrique Pla Ballester, (S.I.P., Trabajos Varios $\mathrm{n}^{\circ} 89$ ), Valencia, 330-338.

GREEN, M., 1992: Dictionary of celtic Myth and Legend, Londres.
MARTÍNEZ, J.M., 1990: «Materiales de la Segunda Edad del Hierro en la Plana de Utiels, Anales de la Academia de Cultura Valenciana (segunda época). Libro-homenaje a J. San Valero Aparisi, Valencia, 75-106.

MOLTÓ, S. y REIG, C., 1996: «La sepultura 53 de la necròpoli ibèrica de La Serreta", Recerques del Museu d'Alcoi, V, 121-135.

NIETO, G. y ESCALERA, A., 1970: "Estudio y tratamiento de una falcata de Almedinilla", Informes y Trabajos del Instituto de Conservación y Restauración de Obras de Arte, Arqueología y Etnología, 10, 5-30.

PRATS, C.; ROVIRA, M.C. y MIRÓ J.H., 1996: «La falcata y la beina damasqinades trobades a la tomba 53 de la necròpoli ibèrica de la Serreta d'Alcoi. Procés de conservació-restauració i estudi tecnològic», Recerques delMuseu d'Alcoi, V, 137-154.

QUESADA, F., 1997: El armamento ibérico. Estudio tipológico, geográfico, funcional, social y simbólico de las armas en la Cultura lbérica (siglos VI-l a.C.), (Monographies Instrumentum 3), 2 vol., Montagnac.

RUBIO, F., 1986: La necrópolis ibérica de La Albufereta de Alicante (Valencia, España), Valencia.

TYLECOTE, R.F. y GILMOUR, B.J.J., 1986: The Metallography of Early Ferrous Edge Tools and Edged Weapons, (BAR British Series 155), Oxford. 